\section{Commentary: Aortic homograft for Warden procedure: Insatiable curiosity}

\author{
Fumiya Yoneyama, MD, and Iki Adachi, MD
}

In this issue of the Journal, Kumar and colleagues ${ }^{1}$ present a case of a 57-year-old female patient with partial anomalous pulmonary venous return of the right upper and middle pulmonary veins entering the superior vena cava 3 to $4 \mathrm{~cm}$ above the cavoatrial junction. To restore the divided superior vena cava and the right atrium, the authors used a non-valved portion of an aortic homograft as an interposition conduit. The authors chose this technique because of the potential benefits of an aortic homograft, such as superior thrombogenicity. In contrast, degenerations and calcifications in the long term remain a matter of concern, as little is known regarding the fate of an aortic homograft in a lowpressure environment.

A potential criticism for the reported procedure is whether there was an absolute need for an aortic homograft to achieve the goal of this operation. In general, aortic homografts are precious materials, with limited supply. Availability is one of the key factors that warrant careful consideration when deciding the use of homograft products. This is in stark contrast to that of prosthetic grafts (with essentially unlimited supply), such as expanded polytetrafluoroethylene. Given the lack of need for growth ability in the adult patient, an expanded polytetrafluoroethylene graft would have been a reasonable option in the reported patient. The use of an autologous pericardium has also been suggested previously, ${ }^{2,3}$ which would likely provide equally favorable thrombogenicity as compared with an aortic homograft.

From the Congenital Heart Surgery, Michael E. DeBakey Department of Surgery, Texas Children's Hospital, Baylor College of Medicine, Houston, Tex.

Disclosures: The authors reported no conflicts of interest.

The Journal policy requires editors and reviewers to disclose conflicts of interest and to decline handling or reviewing manuscripts for which they may have a conflict of interest. The editors and reviewers of this article have no conflicts of interest.

Received for publication Oct 6, 2020; revisions received Oct 6, 2020; accepted for publication Oct 20, 2020; available ahead of print Oct 22, 2020.

Address for reprints: Iki Adachi, MD, Mechanical Circulatory Support, Congenital Heart Surgery, Michael E. DeBakey Department of Surgery, Texas Children's Hospital, Baylor College of Medicine, 6651 Main St, Houston, TX 77030 (E-mail: iadachi@bcm.edu).

JTCVS Techniques 2020;4:274

2666-2507

Copyright $(2020$ The Authors. Published by Elsevier Inc. on behalf of The American Association for Thoracic Surgery. This is an open access article under the CC BY-NCND license (http://creativecommons.org/licenses/by-nc-nd/4.0/).

https://doi.org/10.1016/j.xjtc.2020.10.032

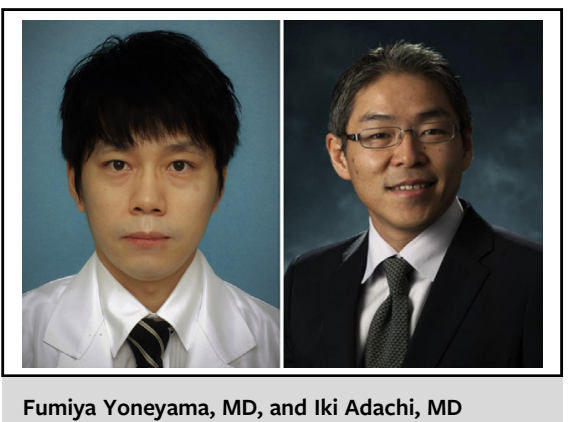

CENTRAL MESSAGE

The unique decision to use an aortic homograft represents insatiable curiosity in striving to achieve excellence. An accumulation of such curiosities has formed the fundamental basis of our specialty.

In any operation, there is almost always multiple different options and strategies upon which the surgeon makes a decision based on his/her own preference and philosophy, as well as the patient's unique characteristics. This is particularly the case in congenital heart surgeries, given the wide variations in the anatomical and physiological substrate of the patient's heart. In turn, that would be what makes congenital heart surgeries endlessly attractive, as no heart is the same as another. The unique decision Kumar and colleagues made in their case is an example of insatiable curiosity in striving to achieve excellence. An accumulation of such curiosities would be what has formed the fundamental basis of our specialty over the last several decades.

\section{References}

1. Kumar TKS, Chen D, Halpern D, Bhatla P, Saharan S, Argilla M, et al. Modified Warden operation using aortic homograft. J Thorac Cardiovasc Surg Tech. 2020;4: 271-3.

2. Tao K, Pan W, Lin K, Shi Y, Zhu P, Guo Y, et al. Modified cavoatrial anastomosis in Warden procedure. Ann Thorac Surg. 2010;89:2047-8.

3. Ling Y, Gan C, Sandeep B, An Q. Modified Warden procedure for partial anomalous pulmonary venous return to the superior vena cava. J Card Surg. 2016;31: 631-4. 